\title{
Generalized Norms of Reaction for Ecological Developmental Biology
}

\author{
Sahotra Sarkar* and Trevon Fuller \\ Biodiversity and Biocultural Conservation Laboratory, Section of Integrative \\ Biology and Department of Philosophy, University of Texas at Austin, 1 Texas \\ Longhorns, \#C3500, Austin, TX 78712-1180.
}

\begin{abstract}
A standard norm of reaction (NoR) is a graphical depiction of the phenotypic value of some trait of an individual genotype in a population as a function an environmental parameter. NoRs thus depict the phenotypic plasticity of a trait. The topological properties of NoRs for sets of different genotypes can be used to infer the presence of (non-linear) genotype-environment interactions. While it is clear that many NoRs are adaptive, it is not yet settled whether their evolutionary etiology should be explained by selection on the mean phenotypic trait values in different environments or whether there are specific genes conferring plasticity. If the second alternative is true the NoR is itself an object of selection. Generalized NoRs depict plasticity at the level of populations or subspecies within a species, species within a genus, or taxa at higher levels. Historically, generalized NoRs have routinely been drawn though rarely explicitly recognized as such. Such generalized NoRs can be used to make evolutionary inferences at higher taxonomic levels in a way analogous to how standard NoRs are used for microevolutionary inferences.
\end{abstract}

Running head: Generalized Norms of Reaction.

Keywords: Norm of reaction, reaction norm, phenotypic plasticity, developmental evolution.

* Corresponding author; e-mail: <sarkar@mail.utexas.edu>; Phone: 1512232 7122;

FAX: 15124714806. 


\section{Introduction.}

After Mendel's work was recovered around 1900, much of the first decade of the twentieth century was spent in articulating a conceptual framework for the study of heredity in which Mendel's rules played a fundamental role. In 1905 Bateson coined the term "genetics" to describe the new discipline (Carlson 1966). A distinction between genotype and phenotype was already implicit in Mendel's original distinction between trait and factor; it was made explicit by Johannsen in 1909 (Johannsen 1909, 1911). That distinction made it perspicuous that factors other than genes, namely, environmental factors played a role in the developmental origin of characters. Working with parthenogenetic pure lines of morphologically distinct strains of Daphnia and Hyalodaphnia collected from different German lakes, Woltereck (1909) seized upon the genotype-phenotype distinction in order to introduce the concept of the norm of reaction (NoR): a graphical representation of the variation in the phenotypic response to environmental variation of a given genotype. Woltereck went on to argue that what was inherited was the totality of these reaction norms. (See Sarkar [1999] for a detailed history.)

By 1914 Nilsson-Ehle (1914) had introduced the concept of phenotypic plasticity to capture phenotypic variation shown by the same genotype in response either to environmental variation or stochastic factors. In the Soviet school of genetics that developed around Chetverikov in the 1920s (Adams 1980), Woltereck's view of inheritance was espoused by most members, including Dobzhansky who, in 1926, effectively equated the NoR with the gene by claiming that the former was a Mendelian unit of inheritance. Thus genes were seen as enabling agents rather than the determinants of the phenotypic fate of individual organisms. Before Lysenko's ascendancy and the subsequent destruction of Soviet genetics in the late 1930s and 1940s, in the Soviet Union this view of inheritance was thought to permit the acceptance of Mendelian genetics without falling either into a hereditarian determinism or a mechanistic view of heredity that would be in conflict with the official ideology of dialectical materialism.

In sharp contrast, the received view of evolution, which historically originates in Western evolutionary genetics, is founded on the assumption that changes at the genetic level are the driving force of evolution at all taxonomic levels. The mechanisms of evolutionary change such as drift and selection are thought ultimately to make their effects felt by acting on blind genetic variation. After his emigration to the West, Dobzhansky was almost the sole proponent of the importance of the NoR in the genetical community of the West before 1965. Yet, in 1937, even he defined evolution as a "change in the genetic composition of populations (Dobzhansky 1937, p. 11)." In the received view, genetic hegemony was established by ignoring the phenotypic plasticity depicted by NoRs that are not flat. Phenotypic variability reflecting 
environmental differences was given a genetic explanation by inventing the concepts of penetrance and expressivity (Vogt 1926): if, in some individuals, the trait failed to manifest itself in spite of an individual having the gene for it, the gene had "incomplete" penetrance; if there was variability in the degree to which the trait was manifested, the gene had "variable" expressivity. In either case, the central agency of the gene in phenogenesis remained unquestioned (Laubichler and Sarkar, in press).

From the evolutionary point of view, the central question that had to be answered by evolutionary genetics was that of the origin of the specific morphological and behavioral organismic traits that extant organisms manifest today. In most cases, the received view of evolution does not have a fully satisfactory answer to this question because, as is by now only too well known, development was never successfully incorporated into the population genetics-based received view of evolution. When Morgan set the program for classical Mendelian genetics around 1910, part of his genius lay in realizing that development can be bracketed during the pursuit of an evolutionary genetics that explained many features of evolution. As he later put it: "Between the characters, that furnish the data for the [Mendelian] theory and the postulated genes, to which the characters are referred, lies the whole field of embryonic development. The theory of the gene, as here formulated, states nothing with respect to the way in which the genes are connected with the end-product or character. The absence of information relating to this interval does not mean that the process of embryonic development is not of interest for genetics . . . but the fact remains that the sorting out of the characters in successive generations can be explained at present without reference to the way in which the gene affects the developmental process (Morgan 1926, p. 26)." There should be little doubt that this program has proved to be remarkably fecund. When classical genetics was conjoined to the mathematical models of Haldane, Fisher and Wright in the 1920s, what resulted is the received view of evolution (Fisher 1930; Wright 1931; Haldane 1932). In the hands of their followers, it has explained much of microevolution at the genetic level and evolutionary changes in those phenotypic traits that have a straightforward relation to the gene, that is, for which there is a simple genotype-phenotype (GP) map.

For the last few years the program of developmental evolution has been to try to provide a more complete answer to the question raised at the beginning of the last paragraph. The program's aim is to answer this question with respect to both morphological and behavioral traits at every level of biological organization and taxonomic hierarchy. An important technique within developmental evolution is the analysis of the GP map, $\Gamma_{e}$, which associates each genotype $g$ in a set of genotypes, $\mathbf{G}$, with a phenotype $p$ from the set of accessible phenotypes, $\mathbf{P}$, that is, $\Gamma_{e}: \mathbf{G} \bullet \mathbf{P}$ (Bärbel et al. 2001; Sarkar et al., in preparation). Thus this map captures the process of development. 
However, this map must be indexed by an environment $e$ from the set of developmental environments $\mathbf{E}$ (that is, there is a different GP map for each e) because the phenotype achieved for any genotype will reflect its developmental history. Each element of $\mathbf{E}$ must be viewed as the entire sequence of environments that the organism encounters during development. A limitation of the GP map is that environmental dependence is not explicitly modeled in such a map. Suppose there is phenotypic plasticity for some trait, and let $e$ and $e^{\prime}$ be different environments. Then the plasticity can only be incorporated by positing two different GP maps, $\Gamma_{e}$ and $\Gamma_{e^{\prime}}$, one for each environment.

Explicit environmental dependence is modeled by the NoR map, $\mathrm{N}_{g}$, which, for a given environment $e$ from the set of environments, $\mathbf{E}$, produces a phenotype $p$ from the set of phenotypes, $\mathbf{P}$, that is, $\mathrm{N}_{g}: \mathbf{E} \rightarrow \mathbf{P}$ As a mathematical structure, the NoR map is the complement of the GP map and has to be indexed by each genotype $g$ belonging to the set of genotypes, $\mathbf{G}$. The topological properties of a set of NoRs for different genotypes within a population allow inferences to be drawn about the nature of genotypeenvironment interactions (Hogben 1933; Lewontin 1974; Sarkar 1998). Whether an analogous claim can be made about the GP map remains unclear. Any such claim should address the often-ignored biological fact that phenotypes do not passively react to their environments; rather they have complicated interactions which include manipulating their environments to their advantage. Together, the GP and NoR maps form the developmental map, $\Delta$, which associates a phenotype $p$ with each pair $(e, g)$ of environments and genotypes, that is, $\Delta: \mathbf{E} \leftarrow \mathbf{G} \bullet \mathbf{P}$ where $\mathbf{E} \times \mathbf{G}$ is the Cartesian product of the sets $\mathbf{E}$ and $\mathbf{G}$. A theory of $\Delta$ remains a task for the future. What can be profitably pursued at present are independent theories of $\Gamma_{e}$ and $\mathrm{N}_{g}$ which will eventually have to be synthesized.

Largely using a historical approach, the purpose of this paper is to explain the use of standard NoRs (Section 2) and then indicate how they are generalized to higher levels of the taxonomic hierarchy (Section 3). This generalization is necessary for the study of macro-evolutionary contexts. These generalized NoRs have quite routinely been constructed though rarely recognized as such. The extent to which generalized NoRs are useful has a bearing on intriguing hierarchical theories of evolution (Gould 2002) which rely on multiple-level selection theory (Frank 1998; Keller 1999; Michod 1999). The final section will return to evolutionary questions and discuss possible contributions that NoRs may make to evolutionary biology (Section 4). 


\section{Standard Norms of Reaction.}

In a NoR, the $x$-axis tracks some environmental variable, and a NoR curve is easiest to interpret if this is a quantitative continuous parameter such as ambient temperature or nutrient level. The $y$-axis tracks the phenotypic value of some character and, once again, a NoR is easiest to interpret if this is a quantitative continuous parameter such as various measures of body size. Each curve is supposed to correspond to a different genotype (see Figure 1). Ideally, each point on the curve is the mean of many measurements on the same genotype so that confidence intervals can be drawn; in practice, historically, this ideal has rarely been honored. If a NoR is flat, the trait has no plasticity; otherwise, the phenotypic value of a trait shows environmental dependence. Plasticity comes if four important forms (Schlichting and Pigliucci 1998, p. 53): amount, pattern (Bradshaw 1965; Schlichting and Levin 1984), rate (Kuiper and Kuiper 1988), and reversibility (Slobodkin 1968; Piersma and Lindstrom 1997). (See Pigliucci [2001] for a recent review of phenotypic plasticity.) What is critically important is that, if NoRs are to be used to elucidate genotype-environment relationships, the different individuals of ostensibly the same genotype which are subjected to different environmental treatments must be identical at every locus. Since Woltereck worked with parthenogenetic animals, this requirement was satisfied. It is also easy to satisfy this requirement for plants that can reproduce vegetatively (see, e. g., Sultan and Bazzaz 1993a, b, c) and other clonal organisms, and almost impossible for species with obligate sexual reproduction.

However, among the first and most commonly cited graphical depictions (see, e. g.: Griffiths et al. 2000) of NoRs were those due to Krafka (1920). These were for the bar-eyed mutation (a reduction in the number of eye facets) in Drosophila melanogaster and does not satisfy the requirement of allelic identity at all loci. The most important subsequent uses of NoRs in the West also used this mutation (Hersch 1930, 1934; Driver 1931; Hogben 1933). These NoRs are usually presented as ones for individual genotypes within a population. However, this is incorrect-they are what will be called generalized NoRs for populations within a species. The significance of generalized NoRs in the present context will be described in the next section.

Though the NoR was adopted by the Soviet school of genetics, and it was incorporated into the theory of "organic selection" developed there by Gause (1947), Schmalhausen (1949), and others (see Section 4), this work produced little insight into how the NoR can be used to elucidate genotype-phenotype relationships. The crucial innovation, on this question, came from Hogben (1933). Using Krafka's (1920) data, Hogben drew NoRs for what he took to be two genotypes. From the fact that the two NoRs were not parallel, Hogben concluded that there was an "interdependence" of nature and nurture. This argument was used by Hogben as evidence against a facile genetic reductionism: the claim that phenogenesis can be given an entirely genetic 
explanation (Sarkar 1998). It formed part of Hogben's critique of eugenics. What this argument shows is that, if NoRs for different genotypes in a population are not all parallel, the phenotypic value of the relevant trait results from a (non-linear) interaction between the genotype and the environment. This technique for detecting such interactions is more sensitive than the analysis of variance. It underscores the relative insensitivity of the analysis of variance for the detection of many types of interaction (Wahlsten 1990a, b). Eventually, this argument became a standard use of NoRs in debates over the developmental origin of complex human traits such as IQ (see below). However, in the 1930s and 1940s, the most influential arguments for significant genotype-environment interactions were Haldane's $(1936,1946)$ algebraic analyses.

Though Hogben is not mentioned by name, Lewontin's (1974) classic, "The Analysis of Variance and the Analysis of Causes," is responsible for developing and popularizing Hogben's important argument and for showing that the analysis of variance may fail to recognize important etiological factors while suggesting incorrect ones. One consequence of this is that the statistical measure of heritability (Lush 1943), which is a ratio of variances, cannot be used to partition genetic and environmental components of traits unless NoRs are parallel. Lewontin's (1974) paper was partly a response to an article in which Jensen (1969) had constructed NoRs for mean error scores in a maze test for two inbred rat strains raised in "normal," "restricted" and "enriched" environments using data from Cooper and Zurek (1958), apparently assuming that each strain was genotypically identical. Except for Fuller (1966), these were probably the first explicit NoRs constructed for mammals. Jensen recognized that, since the NoRs were not even nearly parallel, there was a significant genotype-environment interaction. Nevertheless, he went on to suggest that heritability estimates can be used to partition genotypic and environmental components of intelligence, ignoring the fact that the presence of interactions vitiates any such use of heritability (Moran 1973; Kempthorne 1978; Jacquard 1983; Sarkar 1998). Without explicitly claiming that the ability of rats to solve maze tests is a model for human intelligence, Jensen went on to make the controversial claim that environmental manipulation cannot significantly alter IQ scores (Gould 1981). Platt and Stanislaw (1988) later criticized Jensen's inference on the ground that there was a flaw in Cooper and Zurek's methodology: data describing the normal environment was collected two years prior to the data describing the restricted and enriched environments. However, the methodological error of failing to recognize the significance of the genotype-environment interaction is at least equally egregious. 


\section{Generalized Norms of Reaction.}

Understanding the evolutionary origins of major developmental innovations requires analyses at higher taxonomic levels than genotypes within populations. Generalized NoRs provide a technique for such analysis. A set of NoRs from a "population" can be used to capture the relationship between entities at any two adjacent levels of the taxonomic hierarchy. Just as standard NoRs represent the varying environmental responses of different genotypes within a population, generalized NoRs can be used to represent the varying environmental responses of different populations within a species, different species within a genus, and so on, upwards in the taxonomic hierarchy. In a standard NoR, each point on a curve for a genotype should represent the mean of many measurements of the phenotypic value for several individuals with that genotype. Similarly, in generalized NoRs, each point on the curve represents the mean phenotypic value of such measurements on several sub-species, species, and so on.

For populations and species, generalized NoRs have routinely been drawn though not recognized as such. Almost all NoRs from sexually reproducing species are actually generalized NoRs. For instance, Krafka's (1920) NoRs for the bar-eyed mutants of Drosophila melanogaster treated as identical in genotype those groups of individuals having the mutation, but differing in the strength of its manifestation, irrespective of the rest of their genotypes. These groups were not disjoint; for instance, Krafka drew NoRs for an "unselected" group and two "selected" groups which expressed the mutation very strongly or weakly. Hersh's (1930) synthesis of work on the same mutation treated all homozygous mutant females as identical in genotype. Again working with the same mutation, Driver (1931) treated all members of a highly inbred line as identical in genotype. Hogben (1933) used Krafka's (1920) data. Lewontin (1974) draws NoRs for what he takes to be twenty-one different genotypes of Drosophila pseudoobscura using the data of Dobzhansky and Spassky (1944). However, in Dobzhansky and Spassky's paper, each data point represents a population of between 1131 and 3600 individual fourth chromosome homozygotes which are being represented as single genotypes. There are actually twenty-three different populations (see Figure 2). Except for Krafka's (1920) NoRs, all of these should be interpreted as sets of generalized NoRs of populations of a species; in Krafka's case, only disjoint groups should be used for such an interpretation. Thus, these NoRs can be interpreted as showing "genotype"-environment interactions only in the sense that they show the interactions of the genotypes of the population as a whole with the environment. However, for that inference to be reliable, the population must be adequately sampled.

The data reported in the literature usually do not indicate whether the required randomization was achieved in practice. In Figure 2, the populations used were natural populations of Drosophila pseudoobscura. It is known that 
chromosomes in the natural populations were not randomly sampled. The chromosomes selected were those that were known to produce some, but not too drastic, a difference from the normal viability and developmental rate (Dobzhansky and Spassky 1944). In Figure 3, NoRs have been drawn for the proportion of euphally in eight natural populations of the snail, Bulinus truncatus, near Lagos in Nigeria (Shrag et al. 1994). In this case, there is no information whether the populations were randomly sampled.

Generalized NoRs can also be drawn for different species within a genus. Using data from Mitchell (1976), Figure 4 shows the NoRs for mean leaf area for nine different species of the smartweed or knotweed of the genus Polygonum. There is significant variation in the slopes of the NoRs which indicates species-environment interaction. Once again, for this inference to be reliable, the genotypes within the species must be adequately sampled. The data do not provide this information. Blouin (1992) presents NoRs for logarithm of the size at metamorphosis $(\log [S M])$ and the inverse of the larval period (1/LP) for three species of the treefrog of genus Hyla and correctly interprets them as showing species-environment interaction (Figure 5). However, he confuses the discussion by also using the expression "norm of reaction" to describe plots of the correlation between the two characters $(\log [S M] \times 1 / L P)$.

In principle, there is no reason why generalized NoRs cannot be drawn for even higher taxonomic levels. However, in practice, the problem is likely to be difficult for at least two reasons: (i) phenotypic values for traits of evolutionary interest such as differences in morphological organization or acquisition of evolutionary innovations will be difficult to quantify; (ii) the difficulty of adequate sampling may prove to be prohibitive. The motivation for pursuing such a program is that, besides demonstrating the presence of taxonenvironment interactions, novel evolutionary inferences may be drawn from the topology of such NoR sets in the same was that such inferences are drawn for standard NoRs describing individual genotypes within populations. The phenotypic variability available to evolutionary mechanisms at each level of the taxonomic hierarchy can potentially be tracked using a sequence of generalized NoRs. 


\section{Evolutionary Considerations.}

Returning to standard NoRs, the Soviet school made a sharp distinction between adaptive and non-adaptive NoRs. The former were incorporated into models of "organic selection," originally proposed by Baldwin (1896, 1902), Osborn (1897), and Lloyd Morgan (1900), but ignored subsequently (Huxley 1942), and then independently formulated in the Soviet Union by E. J. Lukin and others around 1936 (Blacher 1982). In Gause's (1947, p. 22) exposition, organic selection was based on four principles: "(1) Organisms frequently respond to environmental changes by adaptive phenotypic modifications. (2) Similar adaptive characters may be genotypically fixed in races normally living in the corresponding environments. (3) It is proved that conversion of modifications into mutations is not possible. (4) Hence modifications can only be substituted by coincident mutations, if the latter are associated with some advantages in the process of natural selection." Gause emphasized that "the possibilities of genotypic response to changed environment are much wider than phenotypic ones" (p. 32). He also argued that specialization and plasticity were to be found in an inverse relation to each other. He ended his 1947 paper with a plea: "We hope that this line of thoughts and investigations will not come to a dead end again. ... It can perhaps be considered as an important beginning of the new trend in biology" (p. 65). The ascendancy of Lysenko ended that possibility within the Soviet Union.

The most influential version of this theory is found in Schmalhausen's (1949) Factors of Evolution. His name for organic selection was "stabilizing selection." The NoR was central to this analysis: "every genotype is characterized by its own specific 'norm of reaction,' which includes adaptive modifications of the organism to different environments." A mutation was a change in the NoR. Apparently unaware of the Soviet work, Waddington (1940a, b; 1942) developed similar ideas in a more rudimentary form. Waddington's (1940a) proposal that development was "canalized" was identical to Schmalhausen's claim of autoregulation of NoRs. However, Waddington, unlike Schmalhausen, placed his ideas centrally within the contemporary framework of Western genetics by arguing that the evolution of canalization seemed similar to that of dominance. In an attempted synthesis of Schmalhausen's and Waddington's ideas with conventional population genetics, Lerner (1954) developed a more general model of "genetic homeostasis."

If NoRs are adaptive, there is presumably an evolutionary story to be told of their etiology: they are likely to be either direct targets of selection or indirect results of selection for traits. In 1965, Bradshaw (1965) published a seminal review of phenotypic plasticity in plants which suggested a model for the evolution of NoRs based on genetic control of plasticity. Bradshaw did not view plasticity to be always adaptive but chose to put his emphasis on adaptive plasticity (Bradshaw 1965, 1973). Positing a dichotomy between the 
plasticity and stability of a trait, he associated the latter with canalization. His most important contribution was to propose that plasticity was under specific genetic control.

If plasticity is under genetic control, it is directly subject to selection. In this scenario, the NoR itself is an object of selection. Alternatively, adaptive NoRs may arise because of direct selection for some other feature such as the mean values of the trait in different environments. In the 1980s the evolutionary etiology of NoRs emerged as a locus of significant theoretical research and controversy: whether NoRs arose as a result of direct selection for genes for plasticity or whether they arose as a result of selection on other traits. Starting in the 1970s, but only gathering momentum in the 1980s, models for the evolution of NoRs had begun to be constructed. This theoretical interest reflected growing experimentation on plasticity. Consistent with the view that the NoR was a target of selection, but with little concern for genetic detail, optimization models began to be constructed in the 1970s (e. g., Huey and Slatkin [1976]) and became a cottage industry in the 1980s. (For details of this history, see Sarkar [in press]). Optimization models generally only dealt with life history traits (e. g., Lively [1986]; Fagen [1987]; Houston and McNamara [1992]; Moran [1992]; Stearns and Koella [1986]; Perrin and Rubin [1990]; Clark and Harwell [1992]; Caswell [1993]). Since these models were silent on genetic detail, they left open the question of the genetic basis on which selection of NoRs was supposed to act. That situation changed in the 1980s.

In 1965 there was not even a single population-genetic model for the evolution of quantitative traits in constant environments. By the 1980s that had changed. As an offshoot of an attempt to elucidate the evolutionary dynamics of quantitative characters, Via and Lande (1985) produced several models for the evolution of adaptive and non-adaptive NoRs. This spawned further work, some consisting of quantitative genetic models and others of "gametic models," that is, models with explicit genetic bases. These two approaches eventually became embroiled in the controversy mentioned before.

The central disputed issue became the question whether adaptive NoRs emerged as direct targets of selection or as by-products of selection acting on traits themselves. Another way of framing this issue is to question whether there are specific "plasticity genes," that is genes that through either their expression or regulatory role modify a trait's expression:

(i) in models without specific plasticity genes, NoRs emerge while selection acts on the means of quantitative traits. Selection is stabilizing: it acts to drive populations towards optima which may or may not be accessible (e. g.: Via and Lande [1985]; Via [1987]; van Tienderen [1991]; Gomulkiewicz and Kirkpatrick [1992]). Via (1994, p. 43) summarized these results: "(1) Selection 
is assumed to act only on the phenotypic character states expressed in the environment in which an individual finds itself at the moment; (2) within each environment, selection acts to move the population towards the optimum phenotype . . .; and (3) evolution in variable environments requires that populations respond to selection . . . in a 'quasi-simultaneous' way. . . . In all these models, the optimum joint phenotype--and thus the optimal reaction norm--will not be attained unless there is sufficient genetic variation for all the character states and their combinations. ... In a few of the models, the optimum phenotype cannot be attained[;] . . . the population evolves until it arrives at the best compromise among different selective forces." What is critical is that selection need not act on plasticity modeled as a distinct trait with its own specific genetic etiology;

(ii) meanwhile, the 1980s also saw the revival of Bradshaw's (1965) hypothesis of the specific genetic control of plasticity (e. g.: Scheiner and Goodnight [1984]; Scheiner and Lyman [1991]; Gavrilets and Scheiner [1993]; Pigliucci and Schlichting (1995); Schlichting and Levin (1984, 1986, 1988, 1990); Schlichting [1986a, b, 1989]; Pigliucci et al. 1999). One way this can be achieved is through regulatory genes controlling character formation. De Jong $(1988,1989,1990)$ began quantitative modeling of variation in plasticity allowing for the existence of specific plasticity genes and independent evolution of plasticity and trait means.

This dispute is yet to be resolved (Via et al. 1995). Suffice it here to note that, at least in one aspect, the dispute may be partly spurious. Quantitative genetic models of the sort invoked in position (i) are silent about the genetic details on which selection may act; the genes involved may be specific regulatory genes that confer plasticity to a trait.

In the context of generalized NoRs, what is of interest is the possibility that they evolve by the same mechanisms as standard NoRs for individual genotypes. If the first of the two alternative positions mentioned above is correct, this will involve selection acting at the level of populations and species rather than individuals. Multiple-level selection theory can then be brought to bear upon the problem, providing that theory with experimental data that it should be able to explain. If the second alternative is correct, there should be homologs of plasticity genes across many different taxa. These possibilities remain to be explored in the future. 


\section{Acknowledgments}

This work was supported by NSF Grant No. SES-0090036 to SS. 


\section{References}

Adams, M. B. 1980. Sergei Chetverikov, the Kol'tsov Institute, and the evolutionary synthesis. In E. Mayr and W. B. Provine (eds.). The Evolutionary Synthesis: Perspectives on the Unification of Biology. Harvard University Press, Cambridge, MA, pp. $242-278$.

Baldwin, J. M. 1896. A new factor in evolution. American Naturalist 30: 441 451.

Baldwin, J. M. 1902. Development and Evolution. Macmillan, New York.

Bärbel, M. R., Stadler, P. F., Wagner, G. P., and Fontana, W. 2001. The topology of the possible: formal spaces underlying patterns of evolutionary change. Journal of Theoretical Biology 213: 241 - 274.

Blacher, L. I. 1982. The Problem of the Inheritance of Acquired Characteristics. Amerind Publishing Co, New Delhi.

Bradshaw, A. D. 1965. Evolutionary Significance of Phenotypic Plasticity in Plants. Advances in Genetics 13: 115 -155.

Bradshaw, A. D. 1973. Environment and Phenotypic Plasticity. Brookhaven Symposia in Biology 25: 74 -94.

Carlson, E. A. 1966. The Gene: A Critical History. W. B. Saunders, Philadelphia.

Caswell, H. 1983. Phenotypic plasticity in life-history traits: demographic effects and evolutionary consequences. American Zoologist 23: 35 -46.

Clark, C. W. and Harvell, C. D. 1992. Inducible defenses and the allocation of resources: a minimal model. American Naturalist 139: 521539.

Cooper, R. M. and Zubek, J. P. 1958. Effects of enriched and restricted early environments on the learning ability of bright and dull rats. Canadian Journal of Psychology 12: $159-164$.

de Jong, G. 1988. Consequences of a model of counter-gradient selection. In G. de Jong (ed.). Population Genetics and Evolution. Springer-Verlag, Berlin, pp. $264-277$.

de Jong, G. 1989. Phenotypically plastic characters in isolated populations. In A. Fontdevilla (ed.). Evolutionary Biology of Transient Unstable Populations. Springer-Verlag, Berlin, pp. $3-18$. 
de Jong, G. 1990. Quantitative genetics of reaction norms. Journal of Evolutionary Biology 3: 447 -468.

Dobzhansky, T. 1937. Genetics and the Origin of Species. Columbia University Press, New York.

Dobzhansky, T. and Spassky, B. 1944. Genetics of natural populations. XI. manifestation of genetic variants in Drosophila pseudoobscura in different environments. Genetics 29: $270-290$.

Driver, E. C. 1931. Temperature and gene expression in Drosophila. Journal of Experimental Zoology 59: 1 -28.

Fagen, R. 1987. Phenotypic plasticity and social environment. Evolutionary Ecology 1: 263 -271.

Fisher, R. A. 1930. The Genetical Theory of Natural Selection. Clarendon Press, Oxford.

Frank, S. A. 1998. Foundations of Social Evolution. Princeton University Press, Princeton.

Fuller, J. L. 1966. Variation in effects of chlorpromazine in three strains of mice. Psychopharmacologia 8: 408 -414.

Gause, G. F. 1947. Problems of evolution. Transactions of the Connecticut Academy of Sciences 37: 17 -68.

Gavrilets, S. and Scheiner, S. M. 1993a. The genetics of phenotypic plasticity. V. Evolution of reaction norm shape. Journal of Evolutionary Biology 6: 31 48.

Gomulkiewicz, R. and Kirkpatrick, M. 1992. Quantitative genetics and the evolution of reaction norms. Evolution 46: 390 -411.

Gould, S. J. 1981. The Mismeasure of Man. Norton, New York.

Gould, S. J. 2002. The Structure of Evolutionary Theory. Harvard University Press, Cambridge, MA.

Griffiths, A., Miller, J., Suzuki, D., Lewontin, R. C., and Gelbart, W. 2000. An Introduction to Genetic Analysis. W. H. Freeman, New York.

Haldane, J. B. S. 1932. The Causes of Evolution. Harper and Brothers, London. 
Haldane, J. B. S. 1936. Some principles of causal analysis in genetics. Erkenntnis 6: $346-357$.

Haldane, J. B. S. 1946. The interaction of nature and nurture. Annals of Eugenics 13: $197-205$.

Hersh, A. H. 1930. The facet-temperature relation in the bar series of Drosophila. Journal of Experimental Zoology 57: 283 -306.

Hersh, A. H. 1934. On Mendelian dominance and the serial order of phenotypic effects in the bar series of Drosophila melanogaster. American Naturalist 68: $186-189$.

Hogben, L. 1933. Nature and Nurture. W. W. Norton, New York.

Houston, A. I. and McNamara, J. M. 1992. Phenotypic plasticity as a statedependent life history decision. Evolutionary Ecology 6: 243 -253.

Huxley, J. S. 1942. Evolution: The Modern Synthesis. London, George Allen \& Unwin.

Jacquard, A. 1983. Heritability: One word, three concepts. Biometrics 39: 465 -477 .

Jensen, A. R. 1969. How much can we boost IQ and scholastic achievement? Harvard Educational Review 39: 1-123.

Johannsen, W. 1909. Elemente der exacten Erblichkeitslehre. Gustav Fischer, Jena.

Johannsen, W. 1911. The genotype conception of heredity. American Naturalist 45: $129-159$.

Keller, L. (ed.). 1999. Levels of Selection in Evolution. Princeton University Press, Princeton.

Kempthorne, O. 1978. Logical, epistemological and statistical aspects of nature-nurture data interpretation. Biometrics 34: 1 -23.

Krafka, J. 1920. The effect of temperature upon facet number in the bar-eyed mutant of Drosophila. Journal of General Physiology 2: 409 -464.

Kuiper, D. and Kuiper, P. J. C. 1988. Phenotypic plasticity in physiological perspective. Oecologia Plantarum 9: 43 -59. 
Laubichler, M. and Sarkar, S. In press. Flies, genes, and brains: Oskar Vogt, Nikolai Timoféeff-Ressovsky, and the origin of the concepts of penetrance and expressivity. In L. S. Parker and R. Ankeny R. (eds.). Medical Genetics, Conceptual Foundations and Classic Questions. Kluwer, Dordrecht.

Lerner, I. M. 1954. Genetic Homeostasis. Oliver and Boyd, Edinburgh.

Lewontin, R. C. 1974. The analysis of variance and the analysis of causes. American Journal of Human Genetics 26: 400 -411.

Lively, C. M. 1986. Canalization versus developmental conversion in a spatially variable environment. American Naturalist 128: 363 -384.

Lloyd Morgan, C. 1900. Animal Behaviour. E. Arnold, London.

Lush, J. L. 1943. Animal Breeding Plans. 2nd ed. Collegiate Press, Ames, IA.

Michod, R. E. 1999. Darwinian Dynamics: Evolutionary Transitions in Fitness and Individuality. Princeton University Press, Princeton.

Moran, P. A. P. 1973. A note on heritability and the correlation between relatives. Annals of Human Genetics 37: 217.

Moran, P. A. P. 1992. The evolutionary maintenance of alternative phenotypes. American Naturalist 139: 971 -989.

Morgan, T. H. 1926. The Theory of the Gene. Yale University Press, New Haven.

Nilsson-Ehle, H. 1914. Vilka erfarenheter hava hittills vunnits rörande möjligheten av växters acklimatisering? Kunglig Landtbruksakadamiens. Handlingar och Tidskrift 53: 537 -572.

Osborn, H. F. 1897. The limits of organic selection. American Naturalist 31: $944-951$.

Perrin, N. and Rubin, J. F. 1990. On dome-shaped norms of reaction for sizeto-age at maturity in fishes. Functional Ecology 4: $53-57$.

Piersma, T. and Lindstrom, A. 1997. Rapid reversible changes in organ size as a component of adaptive behavior. Trends in Ecology and Evolution 12: $134-138$.

Pigliucci, M. 2001. Phenotypic Plasticity: Beyond Nature and Nurture. Johns Hopkins University Press, Baltimore. 
Pigliucci, M., Cammell, K. and Schmitt, J. 1999. Evolution of phenotypic plasticity[:] A comparative approach in the phylogenetic neighbourhood of Arabidopsis thaliana. Journal of Evolutionary Biology 12: 779 -791.

Pigliucci, M. and Schlichting, C. D. 1995. Reaction norms of Arabidopsis (Brassicaceae). III. Response to nutrients in 26 populations from a worldwide collection. American Journal of Botany 82: 1117 -1125.

Platt, S. A. and Sanislow, C. A. 1988. Norm-of-reaction: definition and misinterpretation of animal research. Journal of Comparative Psychology 102: $254-261$.

Sarkar, S. 1998. Genetics and Reductionism. Cambridge University Press, New York.

Sarkar, S. 1999. From the Reaktionsnorm to the adaptive norm: the norm of reaction, 1909 -1960. Biology and Philosophy 14: 235 -252.

Sarkar, S. In press. From the Reaktionsnorm to the evolution of adaptive plasticity: A historical sketch, 1909 -1999. In T. DeWitt, and S. M. Scheiner, (eds.). Phenotypic Plasticity: Functional and Conceptual Approaches. Oxford University Press, New York.

Sarkar, S., Garson, J. and Wang, L. In preparation. How development may direct evolution: some simple models.

Scheiner, S. M. and Goodnight, C. J. 1984. The comparison of phenotypic plasticity and genetic variation in populations of the grass Danthonia spicata. Evolution 38: 845 -855.

Scheiner, S. M. and Lyman, R. F. 1991. The genetics of phenotypic plasticity II. Response to selection. Journal of Evolutionary Biology 4: 23 -50.

Schlichting, C. D. 1986a. The evolution of phenotypic plasticity in plants. Annual Review of Ecology and Systematics 17: 667 -693.

Schlichting, C. D. 1986b. Studies on Phenotypic Plasticity in Annual Phlox. Ph. D. Dissertation, Department of Botany, The University of Texas at Austin.

Schlichting, C. D. 1989. Phenotypic plasticity in Phlox II. Plasticity of character correlations. Oecologica 78: 496 -501.

Schlichting, C. D. and Levin, D. A. 1984. Phenotypic plasticity of the annual Phlox: tests of some hypotheses. American Journal of Botany 71: 252 -260. 
Schlichting, C. D. and Levin, D. A. 1986. Phenotypic plasticity: an evolving character. Biological Journal of the Linnean Society 29: 37 -47.

Schlichting, C. D. and Levin, D. A. 1988. Phenotypic plasticity in Phlox. I. Wild and cultivated populations of $P$. drummondi. American Journal of Botany 75: $161-169$.

Schlichting, C. D. and Levin, D. A. 1990. Phenotypic plasticity in Phlox. III. Variation among natural populations of $P$. drummondi. Journal of Evolutionary Biology 3: 411 -428.

Schmalhausen, I. I. 1949. Factors of Evolution: The Theory of Stabilizing Selection. Blakiston, Philadelphia.

Slobodkin, L. B. 1968. Toward a Predictive Theory of Evolution. In R. C. Lewontin (ed.). Population Biology and Evolution. Syracuse University Press, Syracuse, pp. $187-205$.

Stearns, S. C. and Koella, J. C. 1986. The evolution of phenotypic plasticity in life-history traits: predictions of reaction norms for age and size at maturity. Evolution 40: 893 -913.

Sultan, S. E. and Bazzaz, F. A. 1993a. Phenotypic plasticity in Polygonum persicaria. I. Diversity and uniformity in genotypic norms of reaction to light. Evolution 47: 1009 -1031.

Sultan, S. E. and Bazzaz, F. A. 1993b. Phenotypic plasticity in Polygonum persicaria. II. Norms of reaction to soil moisture and the maintenance of genetic diversity. Evolution 47: $1032-1049$.

Sultan, S. E. and Bazzaz, F. A. 1993c. Phenotypic plasticity in Polygonum persicaria. III. The evolution of ecological breadth for nutrient environment. Evolution 47: $1050-1071$.

van Tienderen, P. H. 1991. Evolution of generalists and specialists in spatially heterogeneous environments. Evolution 45: 1317 -1331.

Via, S. 1987. Genetic constraints on the evolution of phenotypic plasticity. In V. Loeschcke (ed.). Genetic Constrains on Adaptive Evolution. SpringerVerlag, Berlin, pp. $47-69$.

Via, S. 1994. The evolution of phenotypic plasticity: what do we really know? In L. A. Real (ed.). Ecological Genetics. Princeton University Press, Princeton, pp. $35-57$. 
Via, S., Gomulkiewicz, R., de Jong, G., Scheiner, S. M., Schlichting, C. D., and van Tienderen, P. H. 1995. Adaptive phenotypic plasticity: consensus and controversy. Trends in Ecology and Evolution 10: 212 -217.

Via, S. and Lande, R. 1985. Genotype-environment interaction and the evolution of phenotypic plasticity. Evolution 39: $505-522$.

Vogt, O. 1926. Psychiatrisch wichtige Tatsachen der zoologisch-botanischen Systematik. Journal für Psychologie und Neurologie 101: 805 -832.

Waddington, C. H. 1940. The genetic control of wing development in Drosophila. Journal of Genetics 41: 75 -139.

Waddington, C. H. 1940. Organisers and Genes. Cambridge University Press, Cambridge, UK.

Waddington, C. H. 1942. Canalization of development and the inheritance of acquired characters. Nature 150: $563-565$.

Wahlsten, D. 1990a. Insensitivity of the analysis of variance to heredityenvironment interaction. Behavioral and Brain Sciences 13: 109 -120, 155 161.

Wahlsten, D. 1990b. Goals and methods: the study of development versus partitioning of variance. Behavioral and Brain Sciences 13: 146-155.

Woltereck, R. 1909. Weitere experimentelle Untersuchungen über Artveränderung, speziell über das Wesen quantitativer Artunterschiede bei Daphnien. Verhandlungen der deutschen zoologischen Gesellschaft 19: 110 -173 .

Wright, S. 1931. Evolution in Mendelian populations. Genetics 16: 97 -159. 


\section{Figure Captions}

Figure 1. The effect of pure and mixed growing conditions on the relative fitness of three genotypes of Nicotiana tabacum. The data are from Schmitt et al. (1995); $x$-axis - stand type in which the plants were grown; $y$-axis: relative fitness. The relative fitness of the wild type (WT) was assumed to be 1 in both environments. The fitness of the $\mathrm{Y} 10$ and $\mathrm{Y} 12$ transgenic lines, in which the expression of the phytochrome $A$ gene is greater than in wild types, was determined by measuring the dry biomass of plants in single-genotype "pure" stands and "mixed" stands in which one of the transgenic lines was grown with the wild type. Plant density was the same in pure and mixed stands. In Figure 1a, NoRs are drawn for the 3 genotypes after 64 days of growth in the stands, before a dense "canopy" of shoots had formed. In Figure $1 \mathrm{~b}$, NoRs are drawn after 73 days by which time a canopy had formed. Because the NoRs cross, there is a significant genotypeenvironment interaction.

Figure 2. The effect of temperature on viability of Drosophila psuedoobscura. The data are from Dobzhansky and Spassky (1944); $x$ axis-temperature; $y$-axis: the viability of the flies expressed as a percentage of the total number collected from each natural population. For Figure $2 \mathrm{a}$, there were 26 natural populations from which second chromosome homozygotes were collected. For Figure $2 b$ there were 23 natural populations from which fourth chromosome homozygotes were collected. The key refers to different populations.

Figure 3. The effect of sampling period on the proportion of euphallics in 8 populations of hermaphrodite snail, Bulinus truncatus. The data are from (Schrag et al. 1994); $x$-axis-sampling interval; $y$-axis: proportion of euphallics. In this freshwater snail species, the reproductive tract develops a euphallic form capable of self-fertilizing and donating sperm or an aphallic form capable only of self-fertilization. Nigerian populations of the snail were sampled during 3 time intervals: 25 November 1991 -13 December 1991, 14 December 1991 -2 January 1992, and 3 January 1992 -20 January 1992, listed here as 1,2, and 3 . The key lists the different geographical localities in which the samples were collected.

Figure 4. The effect of aquatic submergence on mean leaf area in members of the amphibious genus Polygonum. The data are from (Mitchell 1976); $x$-axis-submergence status of the plant; $y$-axis: average area of the third expanded leaf below the apex. 23 populations of 9 North American species were submerged for 30 days under laboratory conditions simulating summer light and temperature cycles. Standard errors are shown for species in which more than one population was sampled. Data shown for $P$. amphibium represents the mean of strains $P$. amphibium $\mathrm{E}, \mathrm{I}$, and $\mathrm{S}$. 
Figure 5. The effect of food quantity on frog species of the genus Hyla. The data are from (Blouin 1992); $x$-axis-temperature; y-axis: (a) size at metamorphosis; (b) length of larval period. 12 larvae of each species were raised in the laboratory in high $\left(30^{\circ} \mathrm{C}\right)$ or low $\left(25^{\circ} \mathrm{C}\right)$ temperature environments, both of which are within the range of water temperatures encountered in their native habitat (Florida, USA). Mean and standard errors values (not shown) were recorded for each species at each temperature level. 
Figure 1a

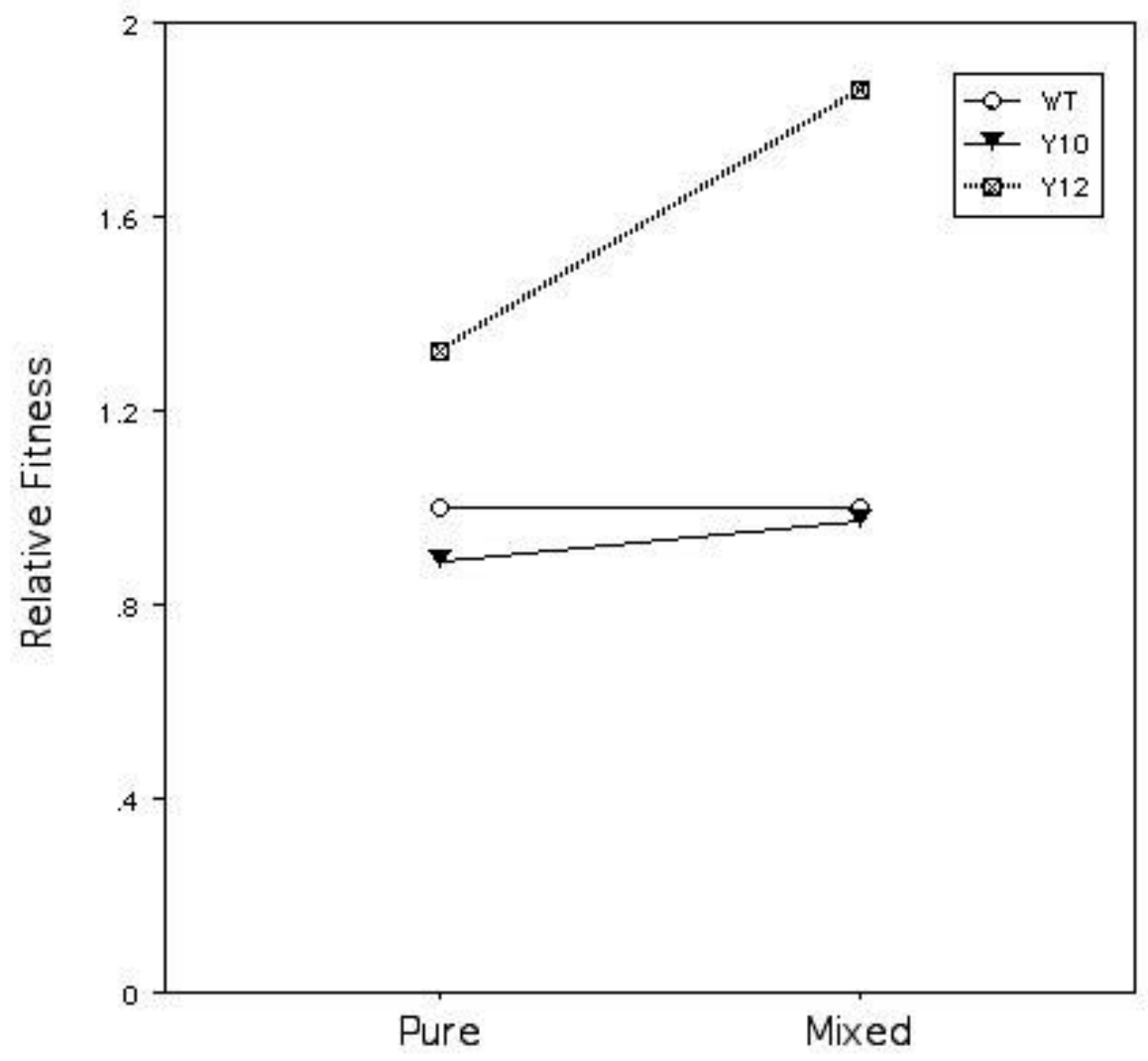


Figure 1b

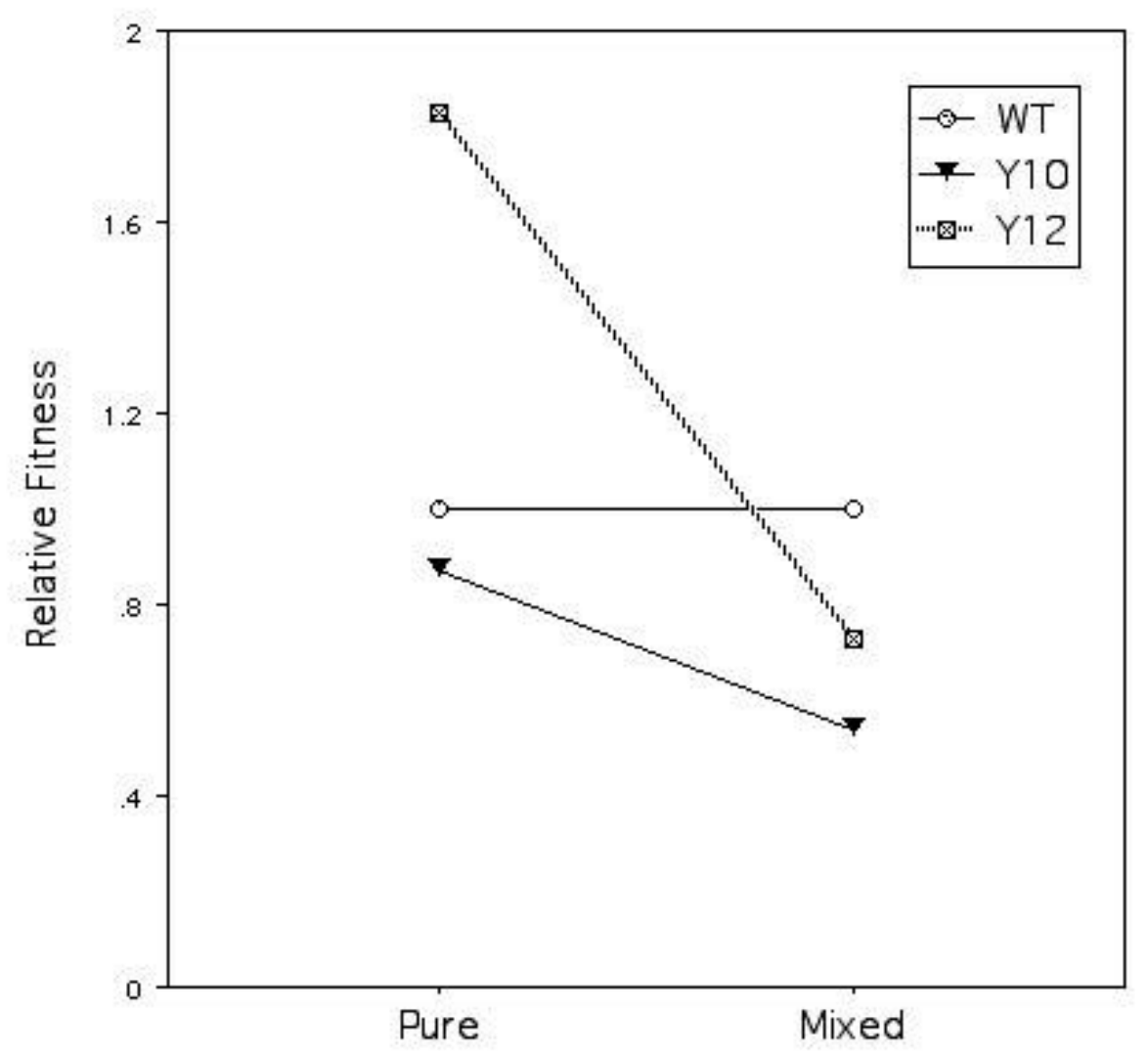


Figure 2a

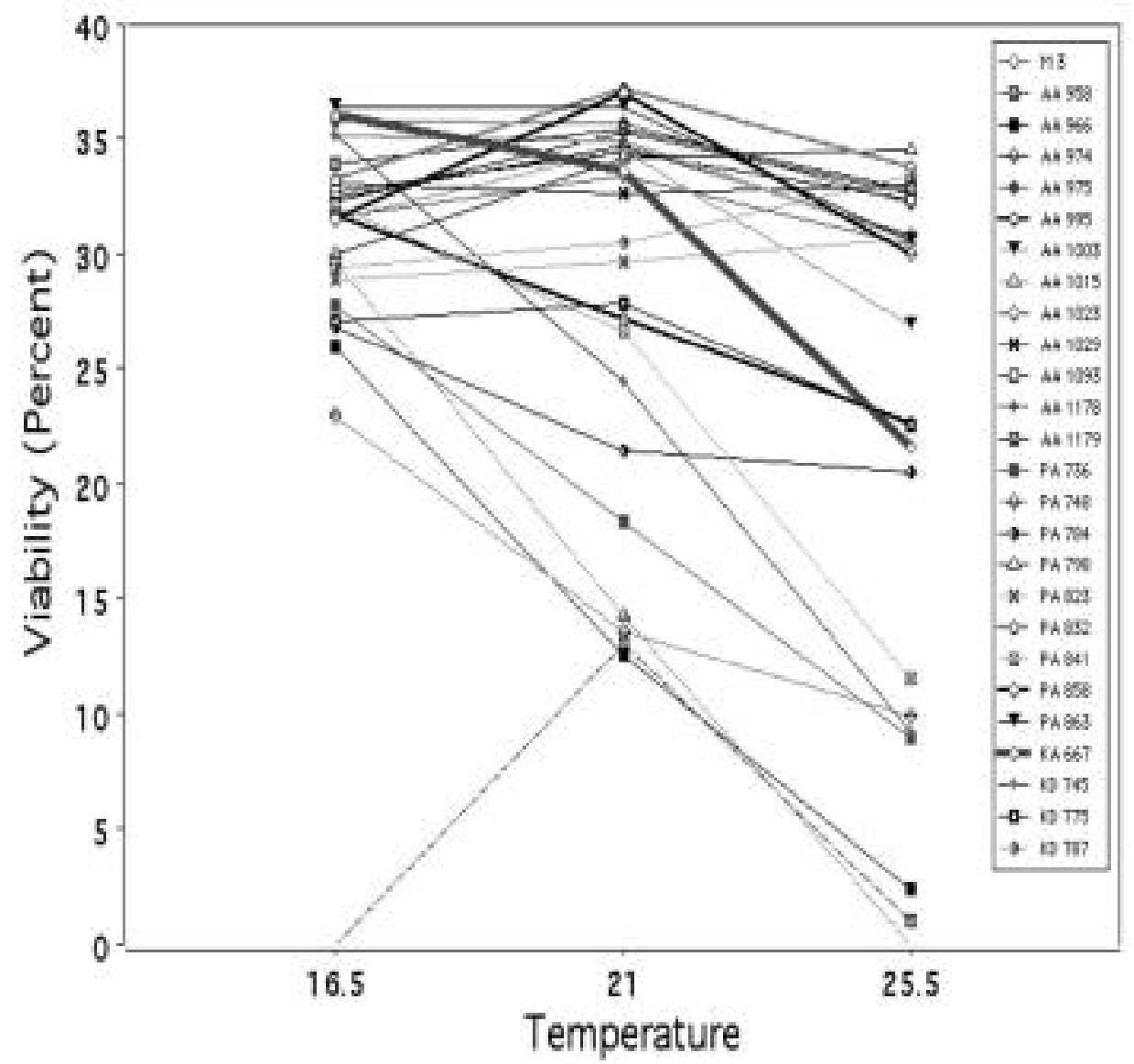


Figure 2b

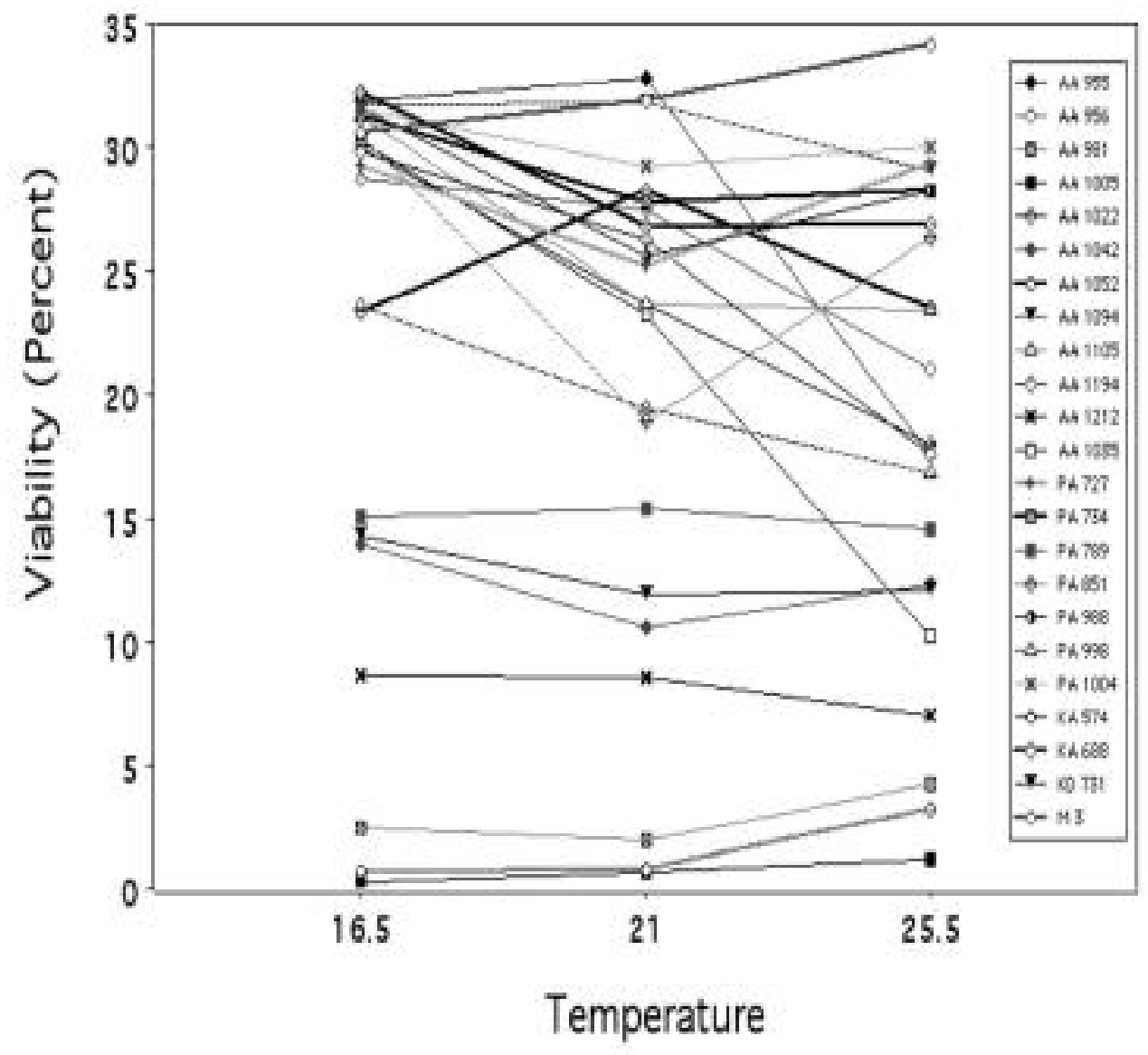


Figure 3

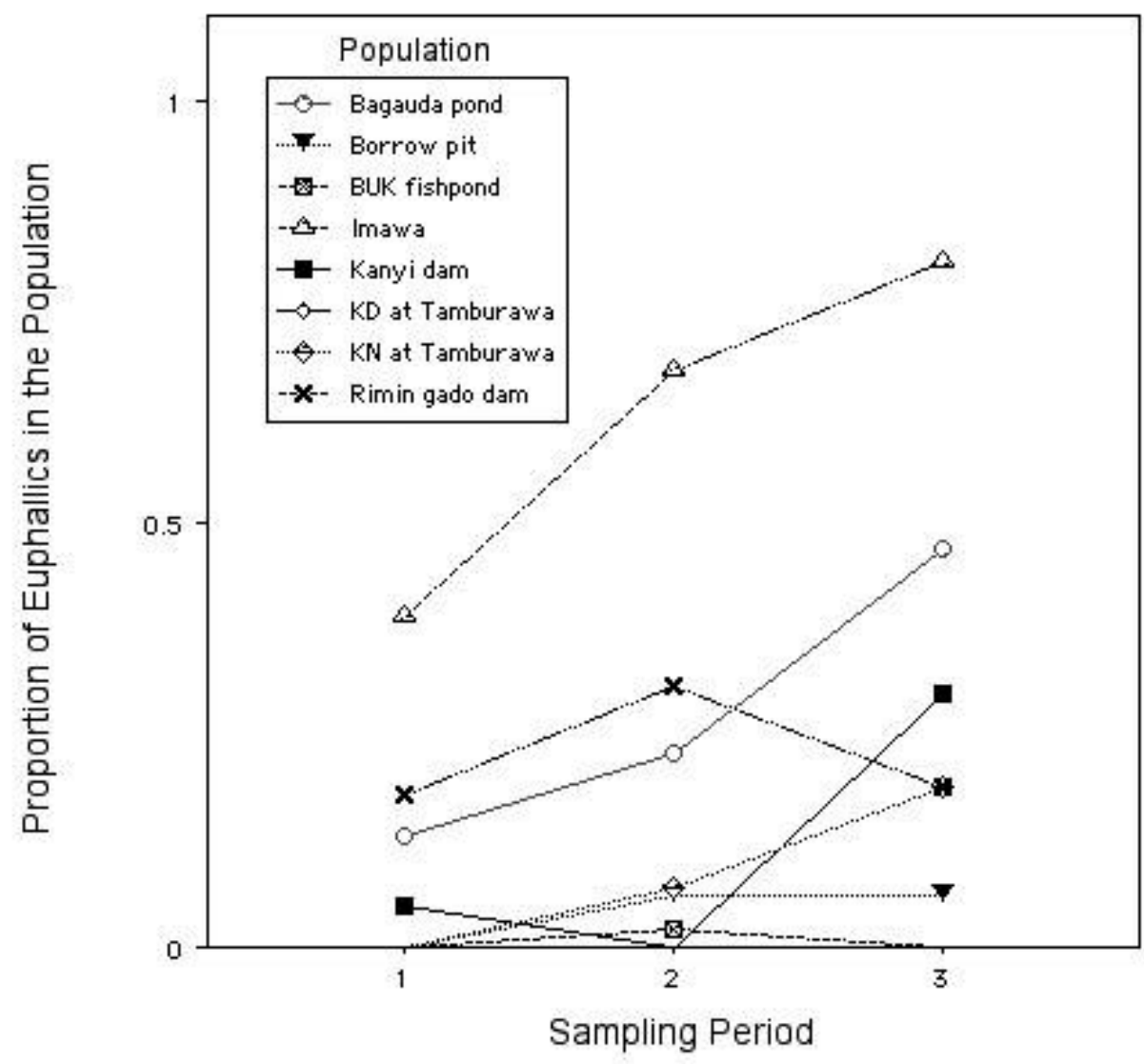


Figure 4

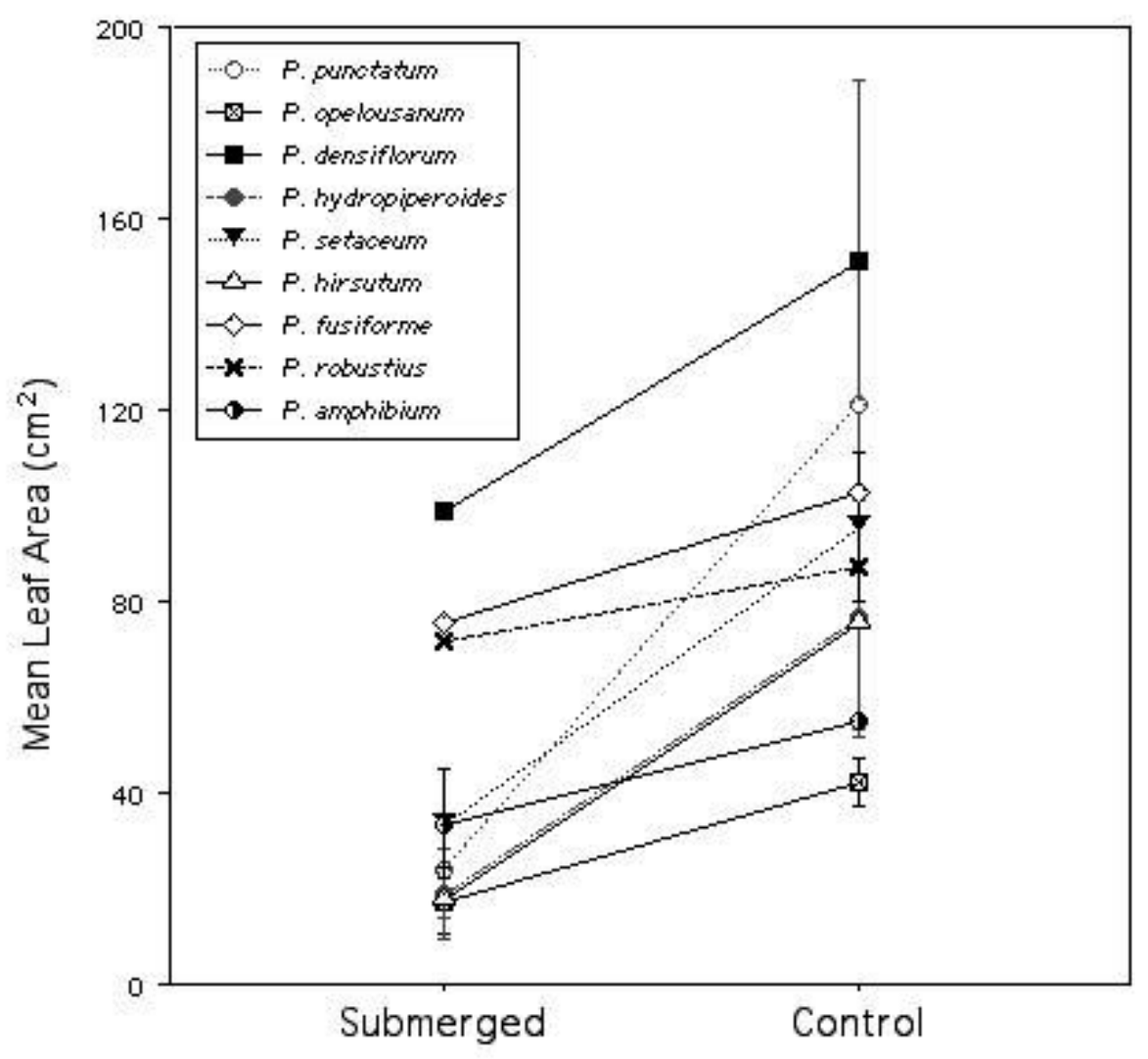


Figure 5a

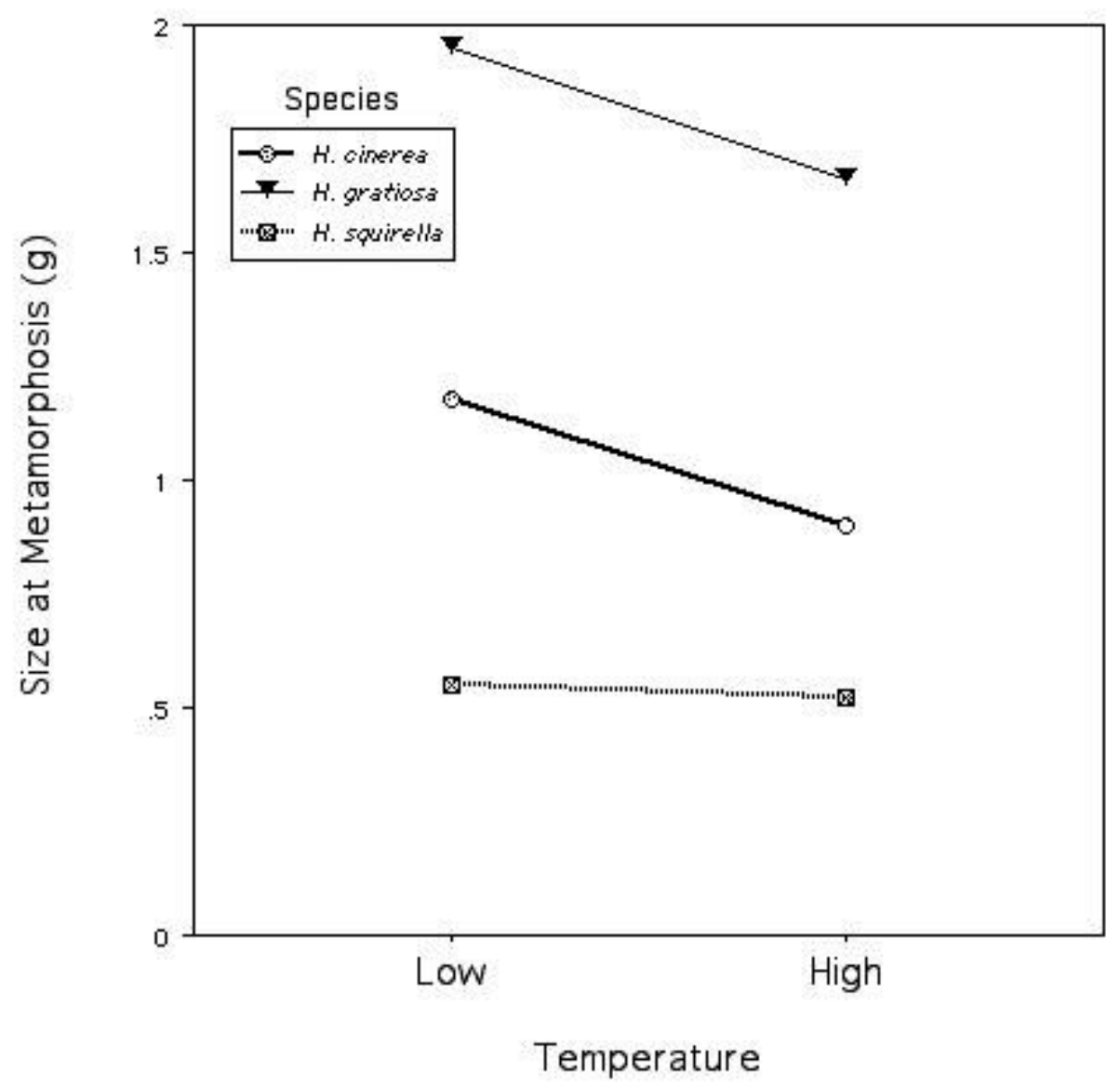


Figure 5b

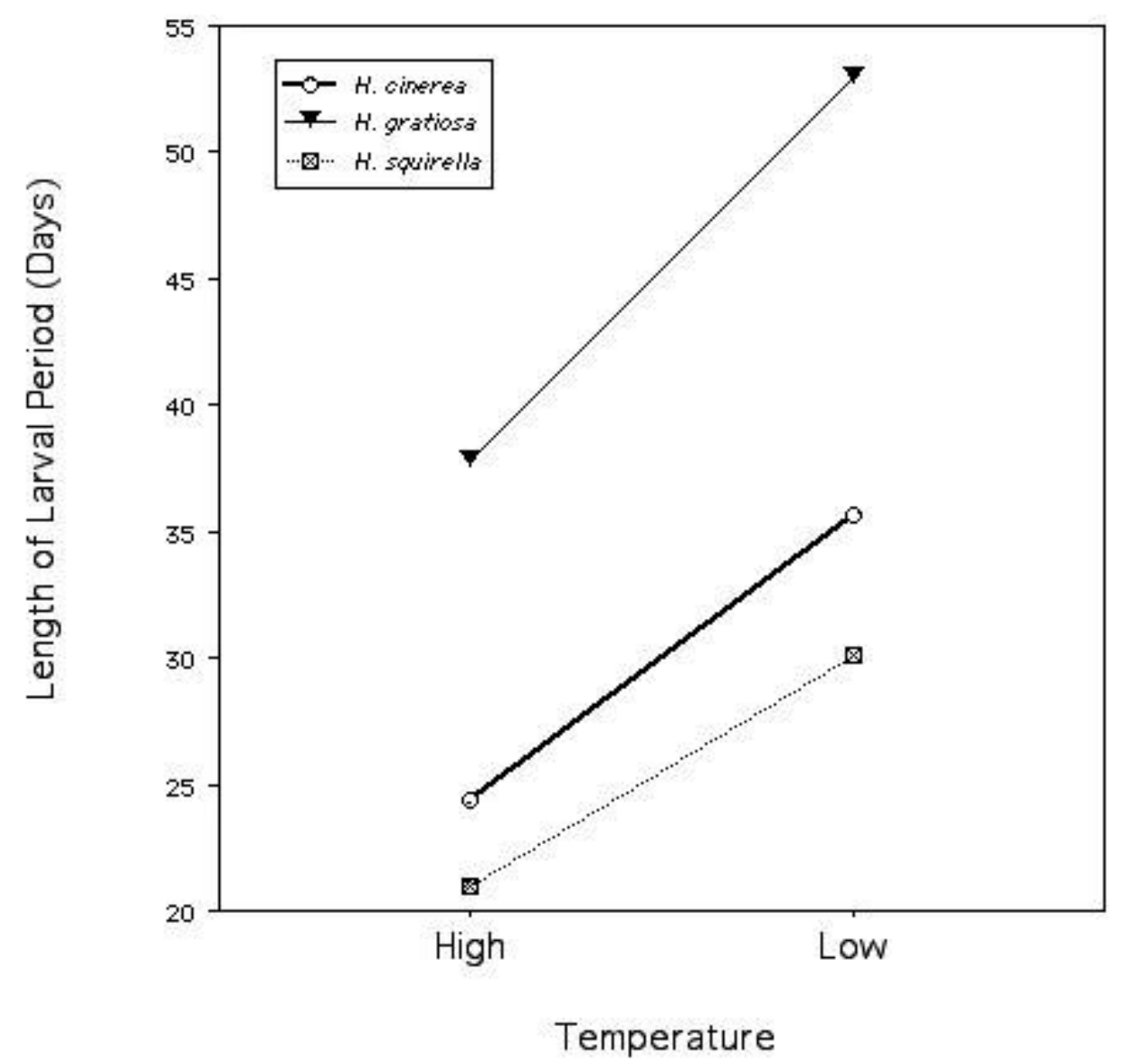

